\title{
Biyoyakıt Bütanolün Metal Organik Kafes (MOF) İçeren Karışık Matrisli UiO-66/PVA Membranlar Kullanılarak Pervaporasyon Prosesi ile Dehidrasyonu
}

\author{
Dehydration of Biofuel Butanol Using Mixed Matrix PVA/UiO-66 Membranes Containing \\ Metal Organic Framework By Pervaporation Process
}

\section{Derya ÜNLÜ*}

Bursa Teknik Üniversitesi, Mühendislik ve Doğa Bilimleri Fakültesi, Kimya Mühendisliği Bölümü, 16310, Bursa, Türkiye

• Geliş tarihi / Received: 06.09.2019 • • Düzeltilerek geliş tarihi / Received in revised form: 22.12.2019 • Kabul tarihi / Accepted: 31.12 .2019

$\ddot{O} z$

$\mathrm{Bu}$ çalışmada geleceğin önemli bir biyoyakıt maddesi olarak görülen bütanolün pervaporasyon ile dehidrasyonu hedeflenmiştir. Bu amaçla UiO-66 yüklü karma matris PVA membranlar sentezlenmiştir. Membranlar çözeltiden döküm ve solvent buharlaştırma tekniği kullanılarak hazırlanmıştır. Saf PVA membrana UiO-66 ilavesinin membranın kimyasal bağ yapısında meydana getirdiği değişim FTIR ile analiz edilmiştir. Membranların morfolojik yapıları ise SEM analizleri ile belirlenmiştir. Membranların besleme karışımındaki bileşenlere ilgisini belirlemek için solvent tutma deneyleri yapılarak su ve bütanol tutma kapasiteleri belirlenmiştir. UiO-66 miktarının, besleme su konsantrasyonunun ve operasyon sıcaklığının membranın ayırma performansına etkisi incelenmiştir. En iyi ayırma performansı ağırlıkça $\% 0.5$ UiO-66 yükleme oranı, ağırlıkça $\% 5$ besleme su konsantrasyonu ve $40^{\circ} \mathrm{C}$ operasyon sicaklığında elde edilmiştir.

Anahtar kelimeler: Biyoyakıt, Bütanol, Pervaporasyon, PVA, UiO-66

\begin{abstract}
In this study, it was aimed to dehydration of butanol which has been seen as biofuel of future by pervaporation. For this purpose, UiO-66 loaded mixed matrix PVA membranes were synthesized. Membranes were prepared by using solution casting and solvent evaporation method. The change of chemical bonds of pristine membrane with addition of UiO-66 was analyzed by using FTIR. Morphological structure of membrane was determined by SEM analysis. In order to determine the affinity of membranes on components in feed mixture, solvent uptake test had been done. Effects of UiO66 amount, feed water concentration and operation temperature were investigated on separation performance. The best separation performance had been determined as 0.5 wt.\% of UiO-66 loading amount, 5 wt.\% of feed water concentration and $40^{\circ} \mathrm{C}$ of temperature.
\end{abstract}

Keywords: Biofuel, Butanol, Pervaporation, PVA, UiO-66

* Derya ÜNLÜ; derya.unlu@btu.edu.tr, Tel: (0224) 30038 28, orcid.org/0000-0001-5240-5876 


\section{Giriş}

Fosil yakıtların tüketimi sonucunda ortaya çıkan küresel 1sınma, fosil yakitlara olan bağl1lığ1 azaltarak yenilenebilir ve sürdürülebilir enerjiye olan ilgiyi önemli derecede arttırmıştır. Biyoyakıtlar, biyolojik proseslerle biyokütleden üretilen ve fosil yakıtlarla yer değiştirebilecek potansiyele sahip önemli bir alternatif yakıt olarak görülmektedirler. Biyoyakitlar arasında biyobütanol benzin ile yer değiştirebilecek geleceğin yakıtı olarak görülen önemli bir enerji kaynağıdır. Biyobütanol, biyoetanol ile karş1laştırıldığında mükemmel yanma performansına ve yüksek oktan sayısına sahiptir. Benzin ve dizel ile modifikasyon gerektirmeden karışabilir olması otomotiv yakıtlarında uygulanabilirliğini arttırmaktadır (Tang vd., 2019). Bütanol genellikle biyokütleden fermantasyon yoluyla üretilmektedir, ancak bütanolün fermantasyon sonucundaki çözelti içerisindeki konsantrasyonu $\% 3$ 'ten daha azdır. Bu nedenle, ayırma işlemi iki aşamadan oluşur: (i) yüksek oranda bütanol ile zenginleştirilmiş bir karışım elde etmek için bütanolün seyreltik sulu çözeltilerden damıtma yoluyla (yaklaşı \% 80.0 bütanol) geri kazanımı, ve (ii) ağırlıç̧a \% 99.5'in üzerinde bir bütanol konsantrasyonuna dehidrasyonu. Bütanol dehidrasyonu için kullanılan geleneksel ayırma prosesleri (distilasyon, ekstraksiyon, adsorpsiyon) oldukça maliyetli ya da yoğun enerji gerektiren proseslerdir. Bütanolün fermantasyon ortamından ayrilmas1 toplam proses maliyetinin \%60-80'ini oluşturmaktadır. Bu da yüksek maliyet anlamına gelmektedir. Bu yüzden etkili ve ekonomik bir ayırma teknolojisinin gelişimi; biyoyakıtların düşük maliyette, ekonomik üretimi için gereklidir (Dong vd., 2014, Liu vd., 2013, Niemisto vd., 2013). Pervaporasyon, kimya ve enerji endüstrisinde distilasyon ve adsorpsiyon gibi geleneksel ayırma prosesleri ile yer değiştirebilecek alternatif bir membran destekli ayırma prosesidir. Pervaporasyon ekonomik, enerji ve çevre dostu bir prosestir (Baker, 2000; Basile vd., 2016). Pervaporasyon prosesi ile 1sıya duyarlı karışımları ve buhar ve sıvı faz dengesinde azeotropik noktaya ulaşan karışımları ayırmak mümkündür (Xu ve Chung, 2017).

Pervaporasyon, membran boyunca kismi buharlaşma ile sıvı karışımların ayrıldığı membran destekli ayırma prosesidir. Pervaporasyon ile ayırma temelde iki adımda gerçekleşir: (i) sıv1 fazdan adsorpsiyon ve membran boyunca difüzyon (ii) buhar fazdan desorpsiyon. Pervaporasyon prosesinde kullanılan membran çözelti içinden seçici olduğu bileşenin geçişine izin vererek ayırma işlemini gerçekleştirmektedir (Huang vd., 2014).

Pervaporasyon membranlarını, polimerik ve inorganik membranlar olarak sinıflandırmak mümkündür. İnorganik membranlar, mükemmel termal, mekanik ve kimyasal dayanıma sahiptirler. Ancak yüksek kırılgan yapıları ve yüksek üretim maliyetleri uygulama alanlarını sınırlar. İnorganik membranlarla kıyaslandığında, polimerik membranlar kolay üretimi, düşük maliyeti ve iyi ayırma performansı gibi avantajlarından dolayı pervaporasyonda yaygin olarak kullanılmaktadırlar. İnorganik membranlar ile polimerik membranların performansını birleştirmek için organik polimerler içerisinde dağıtılmış inorganik dolguları içeren karma matris membranlar sentezlenmektedir. İnorganik partiküllerin, polimerik matrisler içerisine yerleştirilmesi ile yüksek geçirgenlik ve seçicilik özelliklerinin birleştirilerek iyi ayırma performansı sağlanmasının yanında aynı zamanda inorganik membranların sahip olduğu kırılganlık özelliği de ortadan kaldırılmış olunur. Zeolitler, metal oksitler, karbon nanotüpler, grafen oksitler ve metal organik kafes yapılar inorganik dolgu maddesi olarak kullanılmaktadırlar. Bu inorganik dolgular arasinda metal organik kafes yapilar, karma matris membranlar için geniş yüzey alanı, kontrol edilebilir gözeneklilik, yüksek adsorpsiyon kapasitesi ve polimer zincirleri ile uyumluluk gibi özelliklerinden dolayı gelişen malzemeler olarak görülmektedirler (Xu ve Chung, 2017).

Metal-organik kafes yapılar, metal iyonlarının birbirine bağlanması sağlayan organik köprü ligantlar ve metal iyonu ve/veya metal kümelerinin bir araya gelmesi ile oluşan, çok sayıda metal ve organik bağ kombinasyonu ile oluşabilen, yüksek yüzey alanına sahip gözenekli kristal malzemelerdir. Yapılarında bulunan organik bileşenlerden dolayı polimerlerle uyum sorunu yaşamamaktadırlar (Furukawa vd., 2013; Tu vd., 2018). Yüksek yüzey alanlar1, büyük gözenek hacmi gibi istenilen özellikte sentezlenebilmeleri metal organik kafes yapıların kullanım alanlarının çeşitlenmesini sağlamıştır (Dey vd. 2013; Huang vd. 2010). Pervaporasyon ile ayırma işleminde de metal organik kafes yapıların kullanımı son yıllarda oldukça yoğun ilgi görmektedir (Jin vd., 2019; Mao vd., 2019; Hua vd., 2014; Shi vd., 2012).

Metal organik kafes yapılardan biri olan UiO-66, yüksek gözeneklilik, mükemmel kimyasal ve 
termal dayanım gibi pervaporasyon için uygun birçok önemli özelliğe sahiptir. Mükemmel kimyasal dayanım, karboksilat oksijenler ile $\mathrm{Zr}$ atomları arasındaki güçlü asit ve güçlü baz etkileşimleri arasındaki güçlü kovalent bağları ile sağlanmaktadır. Çok geniş pH aralığında suya ve organik solventlere yüksek kimyasal dayanım göstermektedirler (Xu ve Chung, 2017; Wang vd., 2017).

Bu çalışmada geleceğin biyoyakıtı olarak görülen biyobütanolün dehidrasyonu, UiO-66 yüklü karma matris PVA membran ile pervaporasyon prosesi kullanılarak gerçekleştirilmiştir. UiO-66/PVA karma matris membranın bağ yapıları FTIR ile analiz edilmiş, yapısal karakterizasyonu ise SEM analizi ile belirlenmiştir. Biyobütanolün dehidrasyonuna; membran yüklenen UiO-66 miktarının, besleme konsantrasyonunun ve operasyon sıcaklığının etkisi incelenmiştir.

\section{Gereç ve Yöntem}

\subsection{Materyal}

Membran hazırlamada kullanılan polimer PVA Sigma Aldrich, membran çapraz bağlama kimyasalları glutaraldehit Sigma Aldrich, aseton ve hidroklorik asit JT Baker Chemicals firmasından temin edilmiştir. Metal organik kafes yap1 UiO-66 sentezinde kullanılan kimyasallardan terefitalik asit, asetik asit ve dimetilformamid Sigma Aldrich firmasından, zirkonyum klorid ise abcr GmbH firmasından satın alınmıştır.

\subsection{UiO-66 Sentezi}

Ağırlıkça \%0.42 $\mathrm{ZrCl}_{4}$, ağırlıkça \%0.30 terefitalik asit ve hacimce $\% 3$ asetik asit, dimetilformamid (DMF) ile $100^{\circ} \mathrm{C}$ sicaklikta 24 saat boyunca karıştırılmıştır. 24 saatin sonunda karışım oda sıcaklığında soğutulmaya bırakılmıştır. Oda sıcaklığına soğuyan karışım santrifüj edilerek UiO-66 elde edilmiştir. Elde edilen UiO-66 birkaç kez DMF ile yıkanarak kullanıma hazır hale getirilmiştir (Xu ve Chung, 2017).

\subsection{Membran Sentezi}

Ağırlıkça \%5 PVA $90^{\circ} \mathrm{C}$ 'de suda çözülerek polimerik membran çözeltisi hazırlanmıştır. Daha sonra sentezlenen metal organik kafes yapı UiO66 belirlenen oranlarda (PVA miktarının ağırlıkça \%1-5 oranında) membran çözeltisine ilave edilerek homojen bir karışım elde edilinceye kadar manyetik karıştırıcı da karıştırılmıştır. Hazırlanan karma matris membran cam yüzeye dökülerek \%35 bağ1l neme sahip ortamda oda sıcaklığında kurumaya bırakılmıştır. Kuruma işlemi tamamlandıktan sonra membranın suda çözünmesini engellemek için çapraz bağlama işlemi gerçekleştirilmiştir. Çapraz bağlama işlemi $30 \mathrm{ml}$ aseton $10 \mathrm{ml} \mathrm{su}, 2 \mathrm{ml} \mathrm{H}_{2} \mathrm{SO}_{4}$ ve $2 \mathrm{ml}$ glutaraldehitten oluşan çapraz bağ çözeltisinde membranlarin 12 saat bekletilmesi ile gerçekleştirilmiştir. Membran çapraz bağ banyosundan çıkarıldıktan sonra üzerinde kalan kimyasallardan arındırmak için saf su ile yıkanarak kullanıma hazır hale getirilmiştir.

\subsection{Membran Karakterizasyonu}

Membrana ilave edilen UiO-66 metal organik kafes yapının membranın bağ yapılarında meydan getirdiği değişim FTIR ile analiz edilerek saf PVA membran ile karşılaştırma yapılmıştır. Saf ve UiO-66 yüklü PVA membranların morfolojik yapıları ise yüzey görüntüleri alınarak SEM analizi ile belirlenmiştir.

\subsection{Membranların Su Tutma Kapasitesinin Belirlenmesi}

Çalışmada kullanılan membranların beslemedeki bileşenlere ilgisini belirlemek için alkol ve suda, solvent tutma testleri yapılmıştır. A ğırlığı belirlenmiş kuru membran numuneleri bütanol ve suya ayrı ayrı daldırılmıştır. Bütanol ve suda şişen membran numuneleri farklı zaman aralıklarında alınarak öncellikle yüzeyde kalan solvent ve suyu gidermek için filtre kağıdı ile kurulanmış, sonrasında ağırlıklarını belirlemek için tartımları alınmıştır. Membran ağırlığı sabit kalana kadar ölçümlere devam edilmiştir. Membranın ağırlığının sabit kalması, membranın sorpsiyon dengesine ulaştığını göstermektedir. Membranların solvent ve su tutma kapasiteleri Eşitlik 1 kullanılarak hesaplanmıştır.

Su Tutma Kapasitesi $(\%)=\frac{\mathrm{W}_{\text {kuru }}-\mathrm{W}_{\text {denge }}}{\mathrm{W}_{\text {kuru }}}$

Eşitlik 1 'de $\mathrm{W}_{\text {kuru }}$ kuru membranın ağırlığını, $\mathrm{W}_{\text {denge }}$ ise sorpsiyon dengesine ulaşan membranın ağırlığını ifade etmektedir.

\subsection{Biyobütanolün Pervaporasyon ile Dehidrasyonu}

Biyobütanolün dehidrasyonu Şekil 1'de görülen laboratuvar ölçekli pervaporasyon ünitesinde gerçekleştirilmiştir. Pervaporasyon ünitesinde katkısız PVA membran ve bir çeşit metal organik kafes yapı olan UiO-66 yüklü karma matris PVA 
membran kullanılmıştır. Dehidrasyon işleminin istenilen sıcaklıkta gerçekleştirilebilmesi için membran hücresi etüv içerisine yerleştirilmiştir. Böylece sıcaklık kontrolü etüv ile sağlanmıştır. Besleme çözeltisi, ayırma işlemi boyunca membran hücresine yerleştirilen bir mekanik karıştırıcı yardımıyla karıştırılmıştır. Pervaporasyon ünitesinde membran hücresinde besleme karışımının bulunduğu bölüm atmosferik basınçta iken, alt akım vakum basıncı altında 5 mbar'da tutulmuştur. Alt akım ve üst akım arasındaki bu basınç farkı membran boyunca taşınım için bir itici güç oluşturmuştur. Kullanılan membranlar hidrofilik özellikte olduğu için besleme karışımı içerisinden bulunan su membrandan geçerek, alt akımdaki düşük vakum basıncı altında buharlaşarak ayrılmıştır. Buhar fazda elde edilen geçen akım, yoğunlaştırılarak tekrar sıvı fazda elde edilmiştir. Yoğunlaştırma işlemi, sıvı azot ile doldurulmuş geçen akım toplama kapanlarında gerçekleştirilmiştir. Geçen akım toplama kapanlarından alınan numuneler kalibre edilmiş el tipi alkol refraktometresi ve Agilent marka GC-7820A model gaz kromatografi kullanılarak analiz edilmiş, numunedeki bileşen konsantrasyonları belirlenmiştir. Termal iyonlaşma dedektörü ile HP-INNOWAX kapiler kolon kullanılmıştır. Taşıyıcı gaz olarak azotun kullanıldığ 1 analizi metodunda dedektör sıcaklığı $250^{\circ} \mathrm{C}^{\prime}$ dir. Fırın programına göre; 1 dakika $60^{\circ} \mathrm{C}$ sabit sicaklıkta tutulmuş, $\quad 5^{\circ} \mathrm{C} /$ dakika hızla $8 \mathrm{dk}$ 'da $\quad 100^{\circ} \mathrm{C}$ sıcaklığa çıkarılmış, ardından $10^{\circ} \mathrm{C} /$ dakika hızla $220^{\circ} \mathrm{C}$ sıcaklığa çıkarılmıştır.

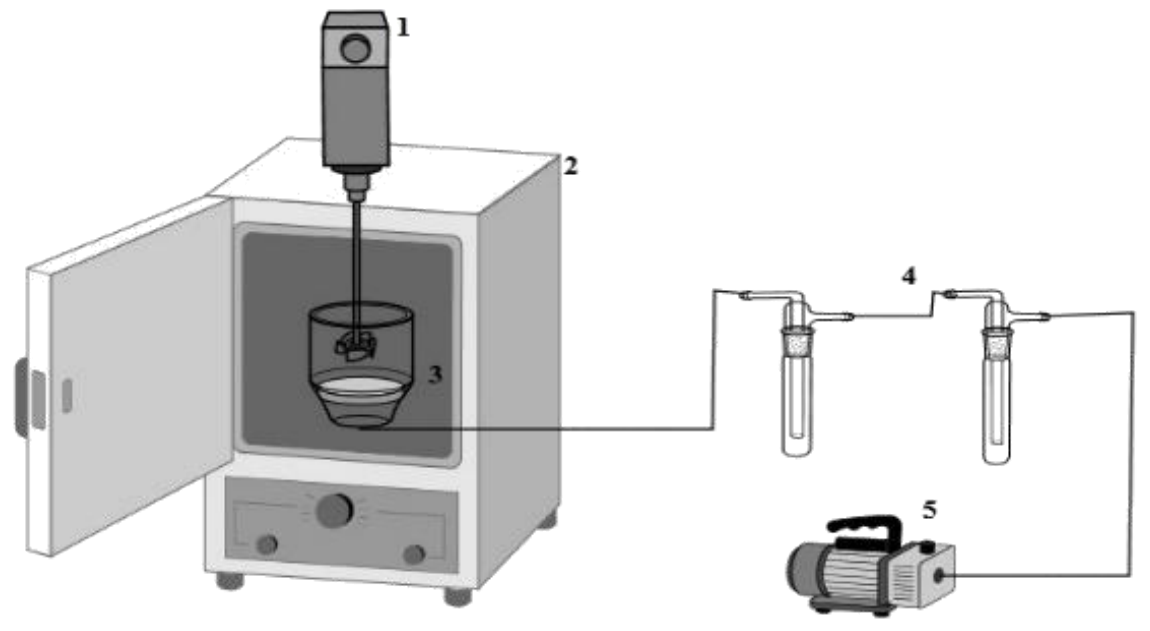

Şekil 1. Pervaporasyon ünitesi (1) Mekanik karıştırıcı (2) etüv (3) membran hücresi (4) geçen akım toplama kapanlar1 (5) vakum pompası

Biyobütanolün dehidrasyonunda kullanılan pervaporasyon prosesinin ayırma başarısı akı ve seçicilik değerleri hesaplanarak belirlenmiştir. Ak1, birim zamanda birim alanda membran boyunca taşınan madde miktarıdır. Kullanılan membranın yüzey alanı $9.62 \mathrm{~cm}^{2}$ olup, belirli zaman aralıklarında alınan numunenin akı değeri Eşitlik 2 kullanılarak hesaplanmıştır.

$$
\mathrm{J}=\frac{\mathrm{m}}{\mathrm{A} \cdot \mathrm{t}}
$$

Buradaki J, akıyı $\left(\mathrm{kg} / \mathrm{m}^{2} . \mathrm{h}\right) ; \mathrm{m}$, kapanlarda biriken numune miktarını $(\mathrm{kg}), \mathrm{A}$; membran alanın $\left(\mathrm{m}^{2}\right)$, $\mathrm{t}$ ise zamanı (saat) göstermektedir.

Seçicilik ise Eşitlik 3 kullanılarak hesaplanmıştır.

$$
\alpha=\frac{\mathrm{C}_{\text {su geçen }} / \mathrm{C}_{\text {bütanol geçen }}}{\mathrm{C}_{\text {su besleme }} / \mathrm{C}_{\text {bütanol besleme }}}
$$

$\mathrm{C}_{\text {su,geçen }}$ ve $\mathrm{C}_{\text {bütanol,gecen, }}$ su ve bütanolün geçen akımdaki konsantrasyonları, $\mathrm{C}_{\text {su,besleme }}$ ve $\mathrm{C}_{\text {bütanol,besleme }}$ ise su ve bütanolün besleme karışımındaki konsantrasyonlarıdır.

\section{Bulgular ve Tartışma}

\subsection{Membran Karakterizasyonu}

Saf PVA membran ile UiO-66 yüklü karma matris membranın FTIR analizleri Şekil 2'de görülmektedir. UiO-66 ilavesinin PVA'nın bağ yapısında belirgin bir değişiklik yapmadığ 
gözlenmiştir. Saf PVA membranın -OH, C-H ve C-OH bağları sirasıyla 3314, 2928 ve $1090 \mathrm{~cm}^{-}$ ${ }^{1}$ 'de görülmektedir (Şekil 2a). UiO-66 yüklü karma matris PVA membranın -OH piki, PVA ile UiO-66 arasında oluşan hidrojen bağlarından dolay1 $3246 \mathrm{~cm}^{-1}$ e kayar (Wu vd., 2018). 1675, $1507,1157,1094,1020$, ve $850 \mathrm{~cm}^{-1}$ de görülen pikler membran içindeki metal organik kafes yapı UiO-66'nın varlığını ifade etmektedir (Şekil $2 b$ ve 2c). Sekiz kez kullanım sonrasında UiO-66 yüklü karma matris membran yeniden analiz edilmiş, membranın kimyasal bağ yapısında değişim olmadığı, yapıdaki UiO-66'ların varlığını koruduğu sonucuna varılmıştır (Şekil 2c).

Şekil 3'te sentezlenen UiO-66 parçacıklarının, saf PVA membranın, kullanılmamış ve kullanılmış UiO-66 yüklü PVA membranların yüzey görüntüleri verilmiştir. Şekil $3 a^{\prime}$ da sentezlenen UiO-66 metal organik kafes yapısı görülmektedir. Membranların SEM görüntülerine bakıldığında ise saf PVA membranın yüzeyinin homojen olduğu ve pürüzsüz bir yüzeye sahip olduğu görülmüştür (Şekil 3b). UiO-66 yüklü PVA membranın ise yüzeyinde görülen açı renkli parçacıklar membranın yapısındaki UiO-66 parçacıklarının varlığını göstermektedir (Şekil 3c). Deneysel çalışmalar esnasında, membranlarda yapısal deformasyon gözlenmemiştir. Sekiz kez ayırma işleminde kullanılan membranın SEM görüntülerine bakıldığında ise membran yüzeyinde UiO-66 parçacıklarının varlığı açıkça görülmektedir (Şekil 3d). Bu durum, membranın kararlı bir aktiviteye ve güçlü bir mekanik dirence sahip olduğunu göstermiştir.

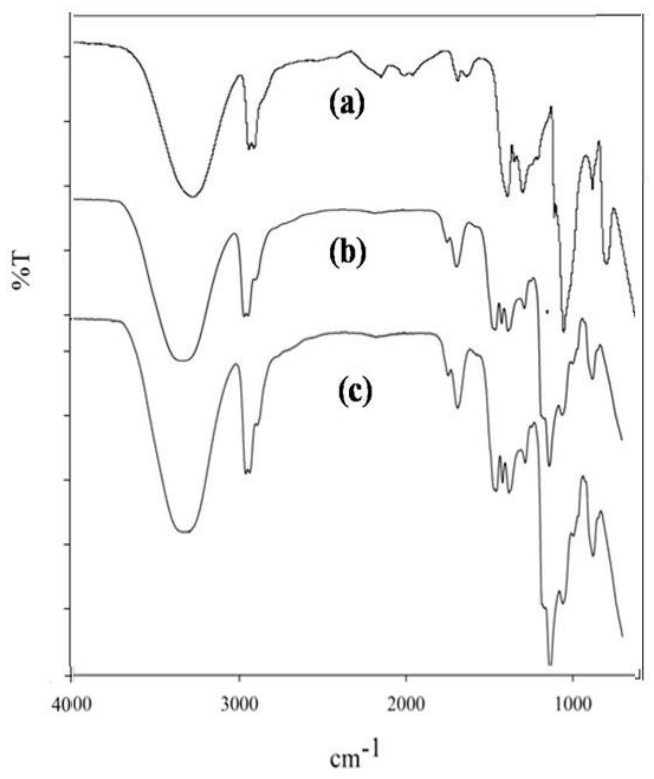

Şekil 2. FTIR spektrumu (a) Saf PVA membran (b) Kullanılmamış UiO-66 yüklü PVA membran (c) Kullanılmış UiO-66 yüklü PVA membran

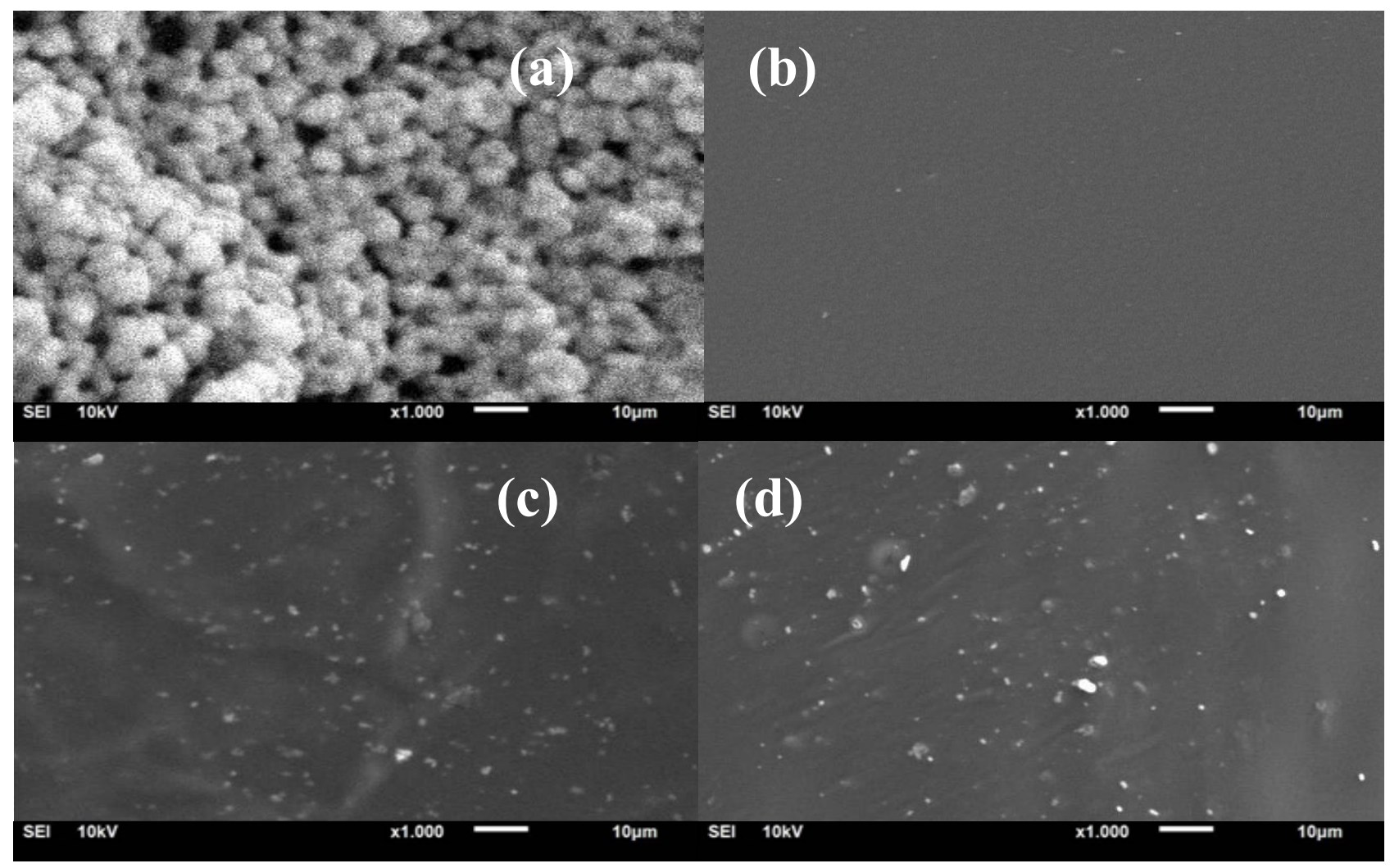

Şekil 3. SEM yüzey görüntüleri (a) UiO-66 (b) Saf PVA membran (c) UiO-66 yüklü PVA membran (d) Ayırmada kullanılmış UiO-66 yüklü PVA membran 


\subsection{Membranların Su Tutma Kapasiteleri}

Solvent ve su tutma kapasitesi membranlarin su ve bütanole olan ilgisi hakkında bilgi vermektedir. UiO-66 yükleme oranı arttıkça su tutma oranı $\% 15$ 'ten \%47'ye artmıştır. Membranlara ilave edilen UiO-66 partikülleri yüksek su çözünürlüğü sağlar. Diğer yandan UiO-66 miktarı arttıkça bütanol tutma oranı azalmıştır. $\mathrm{Bu}$ durum membranın su sorpsiyon yani su çözünürlük seçiciliğinin UiO-66 yüklemesi ile artmasının bir sonucudur. UiO-66 partikülünün ligandı terafitalik asit, hidrofilik fonksiyonel gruplar içermektedir. $\mathrm{Bu}$ fonksiyonel gruplar, su ile etkileşime girerek suyun tutulma miktarını arttırır. $\mathrm{Bu}$ nedenle de UiO-66 oranı arttıkça membranın su tutma kapasitesi artarken, bütanol tutma kapasitesi azalmıştır. Şekil 4'te bu durum açikça görülmektedir.

\subsection{Pervaporasyon Deneyi Sonuçlart}

Metal organik kafes yapıların karma matris membranlara ilavesi, membranlarin ayırma performansını etkileyen önemli bir faktördür. $\mathrm{Bu}$ çalışmada da metal organik kafes yapı UiO-66

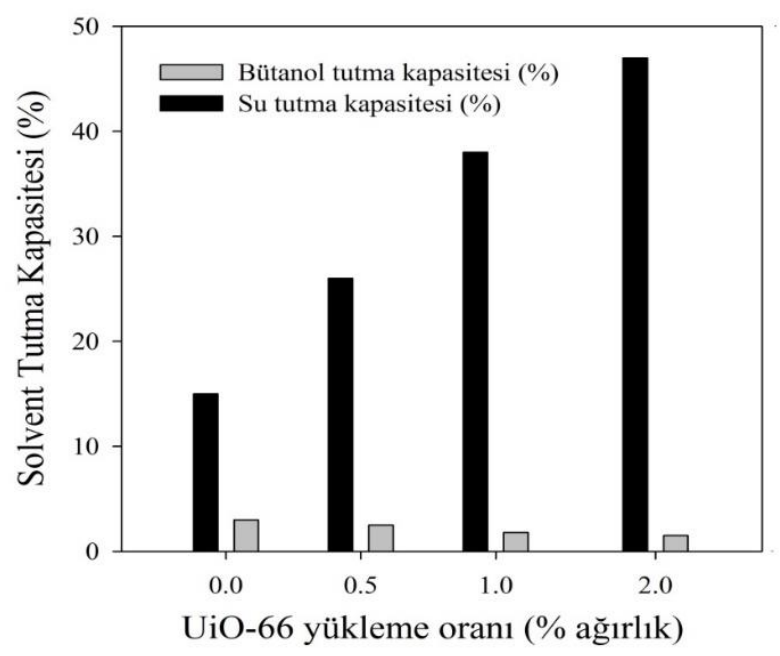

Șekil 4. UiO-66 yükleme oranının solvent tutma kapasitesine etkisi

yüklü karma matris PVA membranları farklı UiO66 yükleme oranlarında hazırlanmıs ve biyobütanolün pervaporasyon ile dehidrasyon işleminde ayırma performansları incelenmiştir. Elde edilen ak1 ve seçicilik değerlerine UiO-66 yükleme oranının etkisi Şekil 5'te verilmiştir.
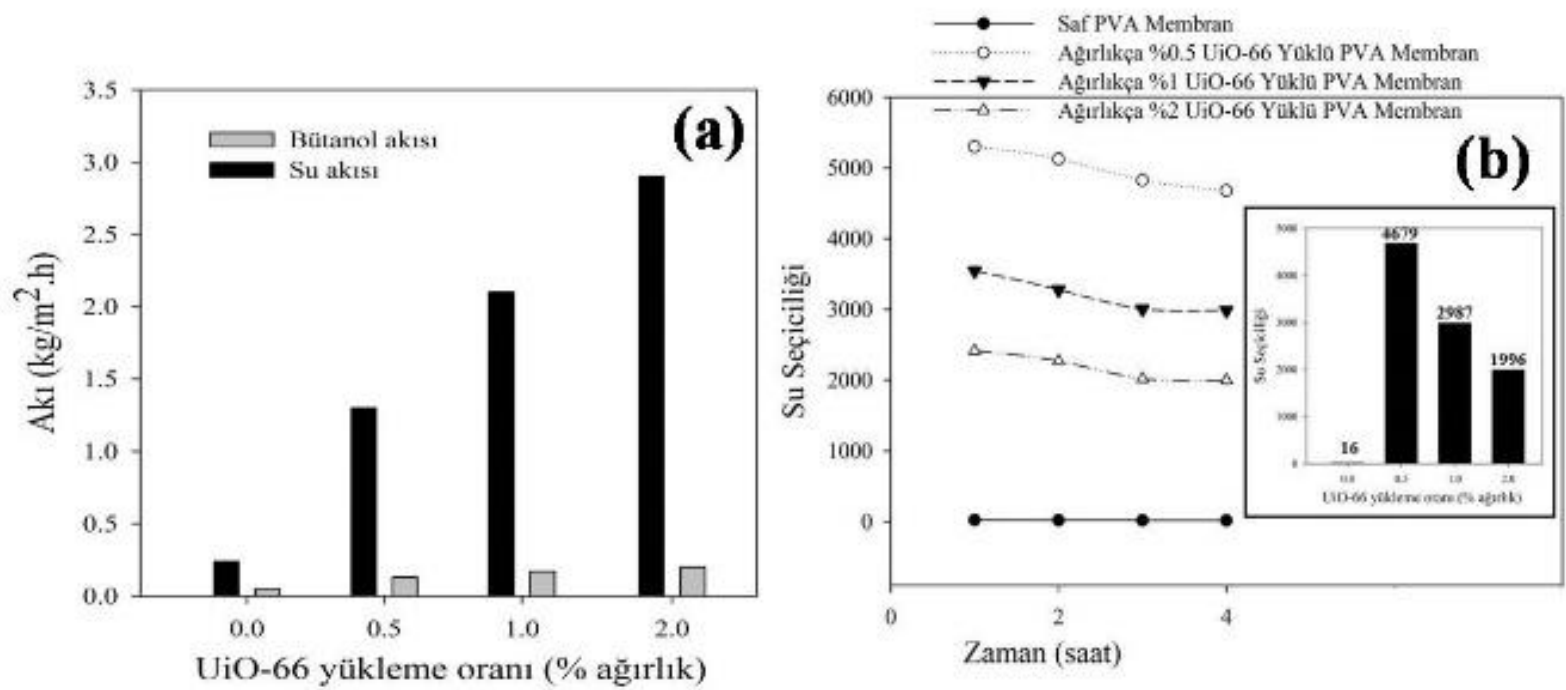

Şekil 5. UiO-66 yükleme oranının akı ve seçiciliğe etkisi $\left(40^{\circ} \mathrm{C}\right.$, ağırlıķa $\% 5$ besleme su konsantrasyonu)

UiO-66 miktarı arttıkça PVA ve UiO-66 arasında kurulan hidrojen bağları ile ilgili olarak membranın sertliği ve dayanımı artmaktadır. PVA'ya ilave edilen UiO-66 membranın hidrofilitesini arttırarak Bölüm 3.2'de de belirtildiği gibi yüksek su tutma kapasitesi gösterir. Ancak membranın şişerek zayıf özellik göstermemesi UiO-66'nın suya dirençli bir yapıya sahip olmas1 nedeniyle UiO-66 ilavesinin membranın mekanik dayanımını da arttırdığını göstermektedir (Liu vd. 2015; Miyamoto vd. 2017). Ancak yapilan su tutma testleri ile ve yapılan literatür araştırmalarına göre, PVA'ya yüksek miktarda UiO-66 yüklemenin aglomerasyona neden olacağ1 ve bunun membranın sertliğini azaltıp, şişmeyi daha fazla arttıracağı öngörülmüștür (Wu vd. 2018). Bu sebeple membrana maksimum $\% 2$ oranında UiO66 eklenmiştir. UiO-66 yükleme oranı membran çözeltisi içerisindeki PVA miktarının ağırlığı 
temel alınarak hesaplanmıştır. Ağırlıkça \%95 bütanol içeren bütanol/su karışımında membranların gösterdiği ayırma performansı Şekil 5 'te görülmektedir. Saf PVA membran 0.24 $\mathrm{kg} / \mathrm{m}^{2}$.h su akısı ve 16 seçicilik değerine sahipken, UiO-66 yüklü karma matris membranların ak1 ve seçicilik değerleri her oranda saf membrandan daha yüksek elde edilmiştir. Ağırlıkça \%0.5, \%1 ve \%2 UiO-66 yüklü karma matris membranların akı değerleri sırasıyla $1.3,2.1,2.9 \mathrm{~kg} / \mathrm{m}^{2} . \mathrm{h}$ iken

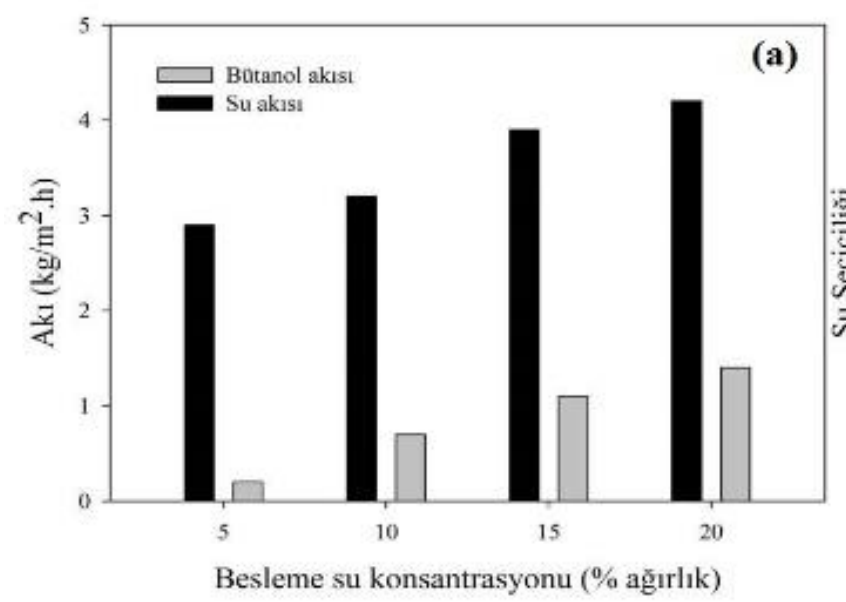

Şekil 6. Besleme su konsantrasyonunun (a) ak1 $\left(40^{\circ} \mathrm{C}\right.$, ağırlıkça $\% 2$ UiO-66 yüklü membran) ve seçiciliğe etkisi $\left(40^{\circ} \mathrm{C}\right)$

Besleme su konsantrasyonu arttıkça kısmi su akısı ile birlikte bütanolün akısı da artmaktadır. Besleme su konsantrasyonu ile akı ilişkisi membrandaki polimer molekülleri ile geçen akımdaki moleküller arasındaki etkileşim ile açıklanmaktadır. Başka bir deyişle PVA hidroksil gruplara sahip hidrofilik bir polimerdir. $\mathrm{Bu}$ yüzden yüksek polariteye sahiptir ve suyla hidrojen bağı yaparak güçlü etkileşimler kurar. Yüksek besleme su konsantrasyonunda çok sayıda su molekülü membran ile temas eder. Bu yüzden daha fazla su molekülü membrana sorplanır. $\mathrm{Bu}$ da membranda yüksek şişme derecesi ile sonuçlanır. Şişmiş membran daha fazla su molekülünün difüze olmasına izin verir ve suyun geçiş akısı, besleme su içeriği arttıç̧a artar. Bütanolün akısı da besleme su konsantrasyonunun artması ile artış gösterir. Suyun polimerik membran üzerinde plastikleştirme etkisi sonucu artan serbest hacim, membrandan bütanolün de difüzyonunu arttırır ve bu durum bütanol akısının da artması ile sonuçlanır. Ancak bütanolün ak1 değeri suyun akı değerinin yanında her zaman daha düşüktür. $\mathrm{Bu}$ durum membranın hidrofilik yapisı ile ilgilidir. PVA hidrofilik bir membran olduğundan suya daha fazla ilgi gösterir. Membran sentezinde kullanılan polimerik malzemeler ile bileşenler arasındaki ilgiyi

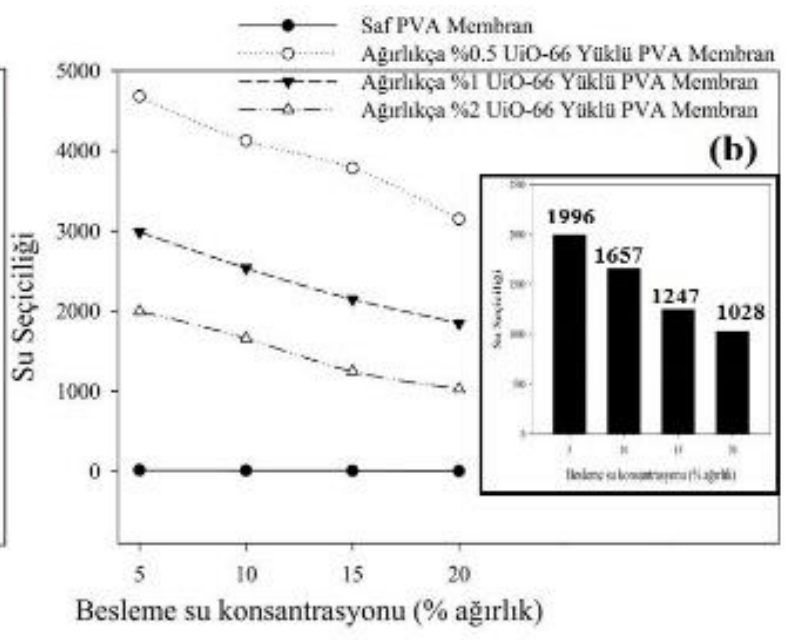

seçicilik değerleri 4679, 2987 ve 1996 olarak elde edilmiştir (Wang vd., 2017). Seçicilik değeri membranın şişmesine bağlı olarak zamanla azalmasına rağmen saf PVA membrana göre oldukça yüksek değerdedir.

Besleme su konsantrasyonunun akı ve seçiciliğe etkisi Şekil 6'da gösterilmiştir. Deneyler $40^{\circ} \mathrm{C}$ sıcaklıkta, ağırlıkça \%2 UiO-66 yüklü membran ile gerçekleştirilmiştir. tanımlamak için en basit yaklaşım çözünürlük parametresidir. PVA'nın ve suyun çözünürlük parametresi sirasıly 39.1 ve $47.9^{\prime}$ dur. Bütanolün ise 16 olarak belirlenmiştir (Tsou vd., 2013). Çözünürlük parametresi teorisine göre bileşenlerin çözünürlük parametreleri değerleri birbirine ne kadar yakınsa, bu durum malzemelerin güçlü etkileşimde olduğunu gösterir. Bu nedenle suyun ak1 ve seçicilik değeri bütanole göre her zaman daha yüksektir. $\mathrm{Su}$ akısındaki artış ile kıyaslandığında bütanol akısının artışı, besleme su konsantrasyonunun artışı ile daha yavaş artış gösterir (Guo vd., 2004, Jalal vd., 2015). Ancak bütanolün akısındaki artış, seçicilik değerlerinde düşüş anlamına gelmektedir. Çünkü membran, asıl hedef olan su ile birlikte bütanolünde geçişine izin vermektedir. $\mathrm{Bu}$ nedenle besleme konsantrasyonu arttıkça bütanol geçişi artmış, suyun seçicilik değeri azalmıştır. Ağırlıkça \%2 UiO-66 yüklü PVA karma matris membran kullanıldığında besleme su konsantrasyonu $\% 5$ 'ten $\% 20$ 'ye arttıkça suyun akı değeri $2.9 \mathrm{~kg} / \mathrm{m}^{2}$.h 'ten $4.2 \mathrm{~kg} / \mathrm{m}^{2}$.h'e artarken seçicilik değeri 1996'dan 1028 'e düşüş göstermiştir. Farklı UiO-66 yükleme oranlarındaki membranlar kıyaslandığında ise en yüksek seçicilik değeri $\% 0.5$ UiO-66 yüklü membranda 3147 olarak elde edilmiştir. 
Sicaklığın membranın ayırma performansına etkisini incelemek için ağırlıkça \%2 UiO-66 yüklü PVA karma matris membran ile \%5 besleme konsantrasyonundaki biyobütanolün pervaporas- yon ile dehidrasyonu deneyleri yapılmıştır. Şekil 7'de sıcaklıkla akı ve seçicilik değerlerinin değişimi görülmektedir.
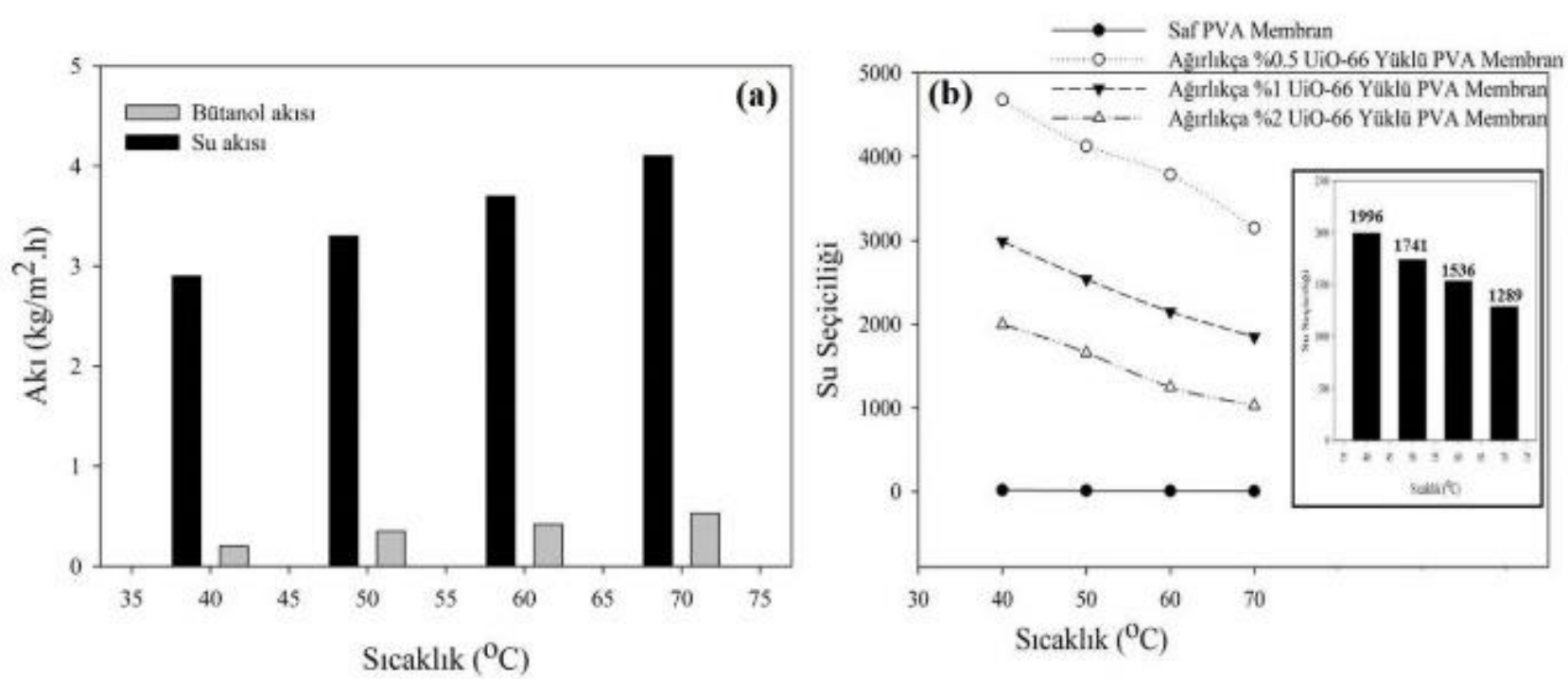

Şekil 7. Sicaklığın (a) akı (ağırlıkça \%5 besleme su konsantrasyonu, ağırlıkça \%2 UiO-66 yüklü membran) ve seçiciliğe etkisi (ağırlıkça \%5 besleme su konsantrasyonu)

Sicaklığın ayırma performansına etkisini yorumlamak için sıcaklıkla membranın yapısal özelliklerinde meydana gelen değişim ile birlikte sıcaklığın itici güce etkisi de incelenmelidir. Sıcaklığın artışı, beslemedeki bileşenlerin doymuş buhar basınçlarını hızlı bir şekilde arttırır. Bu durum, karışımdaki su ve bütanolün membrandan geçiş miktarını arttırır. Bu yüzden su ve bütanolün sıcaklıkla birlikte akılarında görülen artış, itici güçte meydan gelen artış ile açıklanabilir. Bununla birlikte sicaklığın artması, polimer zincirlerinin hareketinin artması ile polimer matriksinde ulaşılabilir daha fazla serbest hacim yaratır ve moleküllerin difüzyonu artar. Suyun difüzyonundaki artış ile birlikte membranın şişme derecesinin artmasına bağlı olarak bütanolünde geçişi artar ve sıcaklık arttıkça bütanolün akısı da artış gösterir. Sicaklık $40^{\circ} \mathrm{C}^{\prime}$ den $70^{\circ} \mathrm{C}^{\prime}$ ye arttıkça suyun akisi $2.9 \mathrm{~kg} / \mathrm{m}^{2}$.h'ten $4.1 \mathrm{~kg} / \mathrm{m}^{2}$.h'e artarken, bütanolün akıs1 da $0.2 \mathrm{~kg} / \mathrm{m}^{2}$.h'ten $0.53 \mathrm{~kg} / \mathrm{m}^{2}$.h'ye artar. Sıcaklık artışı ile bileşenlerin akı değerlerinde artış gözlenirken seçicilik azalır. Membranın seçiciliği, difüzyon seçiciliği ve çözünürlük seçiciliğinden oluşur. Seçicilik değerleri de sıcaklıkla değişim gösterir. Hidrofilik karma matris PVA membran kullanılması dolayısıyla membran, suya yüksek çözünürlük ve difüzyon seçiciliği göstermektedir. Ancak sıcaklık polimer zincirlerinin hareketini arttırdıkça, membran su ve bütanol için daha fazla serbest hacim, daha geniş difüzyon yolu sağlar. $\mathrm{Bu}$ durum, kinetik çap1 daha büyük olan bütanolün (suyun kinetik çapı: 2.6 ve bütanolün kinetik çapı: $5.1 \AA$ ) membrandan transferini kolaylaştırır. Sıcaklık artışı suyun çözünürlük seçiciliğini arttırsa da, su ile birlikte bütanolünde membrandan transfer olması difüzyon seçiciliğini azaltır. Bu iki etkiye bütünü ile bakıldığında membran seçiciliğinin sıcaklıkla azaldığ 1 görülmektedir (Guo vd., 2004, Jalal vd., 2015). Sicaklık $40^{\circ} \mathrm{C}^{\prime}$ den $70^{\circ} \mathrm{C}$ 'ye arttıkça suyun seçicilik değerinin 1996'dan 1289'a düştüğü görülmüştür. Sicaklık arttıkça her UiO-66 yükleme oranında da suyun seçicilik değerinin azaldığı görülmüştür. Çünkü polimer matriksi artan sıcaklıkla esneklik kazanırken, UiO-66 ilavesi de suyun çözünürlüğünü arttırarak membrandan suyun transferini kolaylaştırmıştır. Artan su transferi ve polimer zincirindeki elastikiyet polimerik membranın şişme derecesini arttırarak difüzyon kanallarını genişleteceğinden su ile birlikte bütanolünde membrandan taşınımı gerçekleşir. $\mathrm{Bu}$ nedenle seçicilik azalma göstermektedir. $60^{\circ} \mathrm{C}$ 'de ağırlıkça \%0.5 UiO-66 yüklü membranda su seçiciliği değeri 3785 iken \%2 UiO-66 yüklü membranda bu değer 1247'dir. Bu belirgin düşüş yukarıda ifade edilen çifte etkinin sonucudur.

\subsection{Membranın Tekrar Kullanılabilirliği}

Membranın ayırma performansında tekrar kullanılabilirliğinin etkisi en yüksek ayırma 
performansının elde edildiği, ağırlıkça \%0.5 UiO66 yüklü membran ile $\% 5$ besleme su konsantrasyonunda, $40^{\circ} \mathrm{C}$ sicaklıkta incelenmiştir. Tekrar deneyleri sonucunda elde edilen su akısı ve su seçiciliği değerleri Şekil 8'de gösterilmiştir.

UiO-66 yüklü membran, ayırma işlemi sonucu membran hücresinden çıkarılmış; aynı koşullar altında 8 kez tekrar kullanılmıştır. Her kullanımdan sonra saf su ile yıkanmış, $60^{\circ} \mathrm{C}$ 'de etüvde kurutulmuştur. İlk kullanımdan 8. kullanıma kadar benzer su akısı ve su seçiciliği değerleri elde edilmiştir. İlk kullanım sonrasında $2.9 \mathrm{~kg} / \mathrm{m}^{2}$.h su akısı ve 4679 su seçiliği değeri elde edilirken, membranın tekrar kullanımı sonrasında da bu değerler çok fazla değişim göstermemiş, Şekil 8'den de görüleceği üzere birbirine oldukça yakın değerler elde edilmiştir.

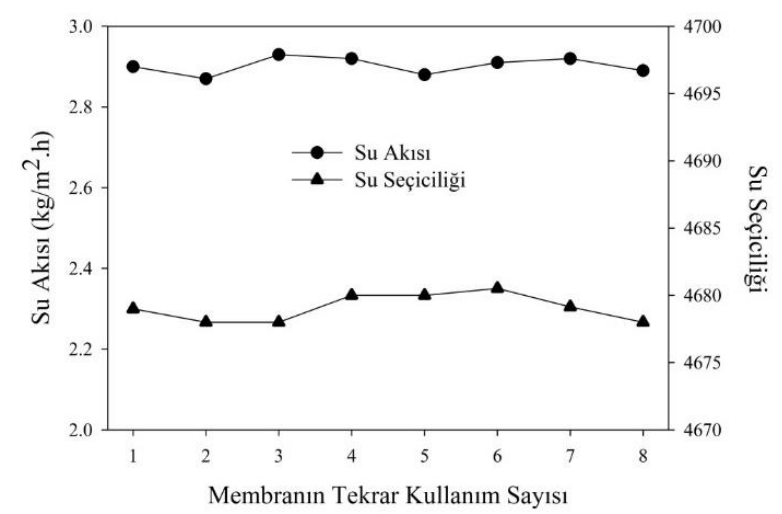

Şekil 8. Membranın tekrar kullanılabilirliği $\left(40^{\circ} \mathrm{C}\right.$, ağırlıkça $\% 5$ besleme su konsantrasyonu, ağırlıkça \% 0.5 UiO-66 yüklü PVA membran)
Elde edilen bu sonuçlar membranın kararlı bir ayırma performansına sahip olduğunu göstermiştir. $\mathrm{Bu}$ nedenle kullanılan membranın, mekanik ve kimyasal olarak kararlı ve tekrar kullanılabilir olduğu sonucuna varılmıştır.

\subsection{Literatür Karşılaştırması}

UiO-66 yüklü karma matris PVA membran kullanılarak bütanolün dehidrasyonunda elde edilen ak1 ve seçicilik değerleri, literatürde pervaporasyon ile ayırma deneylerinde kullanılan UiO-66 yüklü membranların ayırma performansları ile karşılaştırılmıştır. Literatürde, UiO-66 yüklü karma matris PVA membranın bütanolün dehidrasyonunda kullanıldığı çalışmaya rastlanılmamıştır. Literatürde bütanolün zenginleştirilmesi için yapılmış çok sayıda çalışma var iken, hidrofilik membranlarla dehidrasyonu için yapılan çalışma sayısı oldukça azdır. Tablo 1'de bütanolün dehidrasyonunda kullanılan farklı membranların pervaporasyon deneyleri sonucunda elde edilen akı ve seçicilik değerleri verilmiştir.

Tablo 1'de verilen sonuçlara bakıldığında, bu çalışmada kullanılan UiO-66 yüklü karma matris membranların literatürde kullanılan membranlara göre daha yüksek ayırma performansı sergilediği görülmüştür. UiO-66 yüklü karma matris membranların, biyoyakıt bütanolün dehidrasyonunda etkili olduğu, farklı dehidrasyon çalışmalarında da kullanılabileceği sonucuna varılmıştır.

Tablo 1. Ak1 ve seçicilik değerlerinin literatür ile karşılaştırılması

\begin{tabular}{lccccc}
\hline \multicolumn{1}{c}{ Membran } & $\begin{array}{c}\text { Besleme su } \\
\text { konsantrasyonu } \\
(\text { wt. } \%)\end{array}$ & Sicaklık $\left({ }^{\circ} \mathrm{C}\right)$ & $\begin{array}{c}\text { Ak1 } \\
\left(\mathrm{kg} / \mathrm{m}^{2} \mathrm{~h}\right)\end{array}$ & Su seçiciliği & Referans \\
\hline Pervap ${ }^{2} 2510$ & 5 & 80 & 0.8 & 7 & Guo vd., 2004 \\
PVA PERVAP 2510 & 10 & 60 & 0.5 & 3500 & Gallego vd., 2002 \\
GO/mPAN & 10 & 70 & 4.34 & 1791 & Tsou vd., 2013 \\
PVA-SA & 10 & 45 & 0.59 & 606 & Pfromm vd., 2010 \\
PVA/seramik & 5 & 80 & 1 & 450 & Liu vd., 2011 \\
PVA-sitrik asit & 10 & 30 & 0.082 & 171 & Scharnagl vd., 1996 \\
UiO-66/PVA & 5 & 40 & 2.9 & 4679 & Bu çalışma \\
\hline
\end{tabular}




\section{Sonuçlar}

$\mathrm{Bu}$ çalışmada biyoyakıt bütanolün pervaporasyon prosesi ile dehidrasyonu için saf ve UiO-66 yüklü karma matris PVA membranlar sentezlenmiştir. UiO-66 yüklü karma matris membranların ayırma performansının saf membrana göre daha yüksek olduğu görülmüştür. Membrandaki UiO-66 miktarı arttıkça membranın su tutma kapasitesi artarken alkol tutma kapasitesi azalmıștır. Bu da membrandaki UiO-66 miktarı arttıkça su seçiciliğinin artması demektir. UiO-66 partiküllerinin membrandaki varlığı, suyun difüzyonunu ve çözünürlüğünü $\operatorname{arttırdığ~} 1$ için UiO-66 yüklü karma matris PVA membranlarda ak1 ve seçicilik değeri daha yüksek elde edilmiştir. Besleme su konsantrasyonundaki artış, membranın şişme derecesini arttırarak serbest hacmi arttırırken, sıcaklıktaki artış polimer zincirlerin hareketliliğini arttırarak bileşenlerin difüzyonunu kolaylaştırmıştır. $\mathrm{Bu}$ da $\mathrm{su}$ ve bütanolün ak1 değerlerinin artmasına neden olmuştur. Suyun akısı yüksek bir artış gösterirken, bütanolün akısı suya göre daha düşük bir artış göstermiştir. Ancak su ile birlikte bütanolün akısında meydana gelen bu artış, membranın su seçicilik değerlerinin düşmesine neden olmuştur. Membran en yüksek ayırma performansını 2.9 $\mathrm{kg} / \mathrm{m}^{2} \mathrm{~h}$ akı değeri ve 4679 su seçiciliği değeri ile ağırlıç̧a $\% 0.5$ UiO-66 yüklü membran ile $\% 5$ besleme su konsantrasyonunda, $40^{\circ} \mathrm{C}$ sicaklikta göstermiştir. Yapılan deneysel çalışmalar sonucunda UiO-66 yüklü karma matris PVA membranın biyoyakıt bütanolün pervaporasyon prosesi ile dehidrasyonunda oldukça başarılı bir performans sergilediği ve etkili ve seçici bir ayırmanın gerçekleştirilmesi için umut vaat eden bir membran olduğu sonucuna varılmıştır.

\section{Teşekkür}

$\mathrm{Bu}$ çalışma Bursa Teknik Üniversitesi Bilimsel Araştırma Projeleri birimi tarafindan 182N04 numaralı proje kapsamında desteklenmiştir.

\section{Çıkar Çatışması}

$\mathrm{Bu}$ makalede olası bir çıkar çatışması bulunmamaktadır.

\section{Kaynaklar}

Baker, R.W., 2000. Encyclopedia of Separation Science, In Wilson, I.D., Adlard E.D., Cooke M., Poole C. F. (Eds.), Academic Press.Germany. Pp. 205-205.
Basile, A., De Falco M., Centi, G. ve Iaquaniello, G., 2016. Membrane Reactor Engineering: Applications for a Greener Process Industry, Wiley, United Kingdom, 344 p.

Dey, C., Kundu, T., Biswal, B.P., Mallick, A. ve Banerjee, R., 2013. Crystalline metal-organic frameworks (MOFs): synthesis, structure and function. Acta Crystallographica Section B, 70, 3-10.

Dong, Z., Liu, G., Liu, S., Liu, Z. ve Jin, W., 2014. High performance ceramic hollow fiber supported PDMS composite pervaporation membrane for bio-butanol recovery. Journal of Membrane Science, 450, 38-47.

Furukawa, H., Cordova, K.E., O'Keeffe, M. ve Yaghi, O.M., 2013. The chemistry and applications of metal-organic frameworks. Science, 341, 1230444.

Gallego, L.T., Edwards, E., Lobiundo, G. ve Freitas dos Santos, L., 2002. Dehydration of water/tbutanol mixtures by pervaporation: comparative study of commercially available polymeric, microporous silica and zeolite membranes. Journal of Membrane Science, 197(1-2), 309-319.

Guo, W.F., Chung, T.S. ve Matsuura, T. 2004. Pervaporation study on the dehydration of aqueous butanol solutions: a comparison of flux vs. permeance, separation factor vs. selectivity. Journal of Membrane Science, 245(1-2), 199-210.

Hua, D., Ong, Y.K., Wang, Y., Yang, T. ve Chung, T.S., 2014. ZIF-90/P84 mixed matrix membranes for pervaporation dehydration of isopropanol. Journal of Membrane Science, 453, 155-167.

Huang, A., Bux, H., Steinbach, F. ve Caro, J., 2010. Molecular-Sieve Membrane with Hydrogen Permselectivity: ZIF-22 in LTA Topology Prepared with 3-Aminopropyltriethoxysilane as Covalent Linker. Angewandte Chemie International Edition, 49, 4958-4961.

Huang, B., Liu, Q., Caro, J. ve Huang, A., 2014. Isobutanol dehydration by pervaporation using zeolite LTA membranes prepared on 3aminopropyltriethoxysilane-modified alumina tubes. Journal of Membrane Science, 455, 200-206.

Jalal, T.A., Bettahalli, N.M.S., Le, N.L. ve Nunes, S.P., $2015 . \quad H y d r o p h o b i c$ Hyflon $\mathrm{AD} /$ Poly(vinylidene fluoride) Membranes for Butanol Dehydration via Pervaporation. Industrial \& Engineering Chemistry Research, 54(44), 11180-11187. 
Jin, H., Mo, K., Wen, F. ve Li, Y., 2019. Preparation and pervaporation performance of CAU-10-H MOF membranes. Journal of Membrane Science, 577, 129-136.

Liu, S., Liu, G., Zhao, X. ve Jin, W., 2013. Hydrophobic-ZIF-71 filled PEBA mixed matrix membranes for recovery of biobutanol via pervaporation. Journal of Membrane Science, 446, 181-188.

Liu, X., Demir, N.K., Wu, Z. ve Li, K., 2015. Highly Water-Stable Zirconium Metal-Organic Framework UiO-66 Membranes Supported on Alumina Hollow Fibers for Desalination. Journal of the American Chemical Society, 137(22), 6999-7002.

Liu, X., Li, Y., Liu, Y., Zhu, G., Liu, J. ve Yang, W., 2011. Capillary supported ultrathin homogeneous silicalitepoly(dimethylsiloxane) nanocomposite membrane for bio-butanol recovery. Journal of Membrane Science, 369(1-2), 228-232.

Mao, H., Zhen, H.G., Ahmad, A., Zhang, A.S. ve Zhao, Z.P., 2019. In situ fabrication of MOF nanoparticles in PDMS membrane via interfacial synthesis for enhanced ethanol permselective pervaporation. Journal of Membrane Science, 573, 344-358.

Miyamoto, M., Hori, K., Goshima, T., Takaya, N., Oumi, Y. ve Uemiya, S., 2017. An Organoselective Zirconium-Based MetalOrganic-Framework UiO-66 Membrane for Pervaporation. European Journal of Inorganic Chemistry, 2017(14), 2094-2099.

Niemistö, J., Kujawski, W. ve Keiski, R.L., 2013. Pervaporation performance of composite poly(dimethyl siloxane) membrane for butanol recovery from model solutions. Journal of Membrane Science, 434, 55-64.

Pfromm, P.H., Amanor-Boadu, V., Nelson, R., Vadlani, P. ve Madl, R., 2010. Bio-butanol vs. bio-ethanol: A technical and economic assessment for corn and switchgrass fermented by yeast or Clostridium acetobutylicum. Biomass and Bioenergy, 34(4), 515-524.
Scharnagl, N., Peinemann, K.V., Wenzlaff, A., Schwarz, H.H. ve Behling, R.D., 1996. Dehydration of organic compounds with SYMPLEX composite membranes. Journal of Membrane Science, 113(1), 1-5.

Shi, G.M., Yang, T. ve Chung, T.S., 2012. Polybenzimidazole (PBI)/zeolitic imidazolate frameworks (ZIF-8) mixed matrix membranes for pervaporation dehydration of alcohols. Journal of Membrane Science, 415-416, 577586.

Tang, W., Lou, H., Li, Y., Kong, X., Wu, Y. ve Gu, X., 2019. Ionic liquid modified graphene oxidePEBA mixed matrix membrane for pervaporation of butanol aqueous solutions. Journal of Membrane Science, 581 (1), 93104.

Tsou, C.-H., An, Q.F., Lo, S.C., De Guzman, M., Hung, W.S., Hu, C.C., Lee, K.R. ve Lai, J.Y. 2015. Effect of microstructure of graphene oxide fabricated through different selfassembly techniques on 1-butanol dehydration. Journal of Membrane Science, 477, 93-100.

Tu, T.N., Nguyen, M.V., Nguyen, H.L., Yuliarto, B., Cordova K.E. ve Demir S., 2018. Designing bipyridine-functionalized zirconium metalorganic frameworks as a platform for clean energy and other emerging applications. Coordination Chemistry Reviews, 364, 33-50.

Wang, N., Zhang, G., Wang, L., Li, J., An, Q. ve Ji, S., 2017. Pervaporation dehydration of acetic acid using $\mathrm{NH}_{2}$-UiO-66/PEI mixed matrix membranes. Separation and Purification Technology, 186, 20-27.

Wu, G., Li, Y., Geng, Y., Lu, X. ve Jia, Z., 2018. Adjustable pervaporation performance of $\mathrm{Zr}$ MOFs/poly(vinyl alcohol) mixed matrix membranes. Journal of Chemical Technology and Biotechnology. 94(3), 973-981.

Xu, Y.M. ve Chung, T.S., 2017. High-performance UiO-66/polyimide mixed matrix membranes for ethanol, isopropanol and n-butanol dehydration via pervaporation. Journal of Membrane Science, 531, 16-26. 